\title{
Qualitative and quantitative pathology of clinically relevant thermal lesions
}

\section{Sharon Thomsen}

Sharon Thomsen M.D., "Qualitative and quantitative pathology of clinically relevant thermal lesions," Proc. SPIE 10297, Matching the Energy Source to the Clinical Need: A Critical Review, 102970H (24 January 2000); doi: 10.1117/12.375218

SPIE. Event: Digital Optical Computing, 1990, Los Angeles, United States 


\title{
Qualitative and Quantitative Pathology of Clinically Relevant Thermal Lesions
}

\author{
Sharon Thomsen, M. D. \\ Biomedical Engineering Program, University of Texas, Austin, TX 78712 \\ Key Words: Heat, Thermal Therapy, Pathology, Biologic Tissue, Laser, Radio \\ Frequency, Microwave Frequency, Ultrasound, Histopathology, Experiment \\ Planning
}

\section{INTRODUCTION}

Cautery, the application of hot fluids, burning sticks, hot coals or heated metal rods for treatment of disease, has been used to control of bleeding and treat wounds, ulcers and tumors since Neolithic times. [1-6] It has only been in the last 130 years that various electromagnetic energy sources have been exploited to produce heat for thermal medical treatments. $[1,7,8]$ These sources include lasers (light) and radiofrequency, microwave frequency and ultrasound generators. [8] Currently, the heat generated by the interaction of these energy frequencies with targeted biologic tissues is being used to treat superficial and deep lesions for a variety of lesions in several different organs.

The efficacy of modern ablation and coagulation thermal therapies is governed by 1) the patient, his/her disease, target tissue anatomy and desired treatment outcome, 2) the properties and characteristics of the various source energies, 3) the energy delivery systems, 4) the physical properties of the target tissues relative to the applied energy and generated heat, and 5) the mechanisms of heat generation resulting from the interactions of the applied energies and the target tissues.

\section{PATHOLOGIC ASSESSMENT}

Routine qualitative and quantitative gross and histologic pathologic techniques provide powerful tools for evaluation of these factors. Pathologic observations are useful for 1) discovering mechanism(s) of heat treatment effect, 2) mapping the extent of thermal effect and 3) providing measurements for comparisons of instrument design, energy sources and treatment effects. [9] In addition, pathologic evaluation illuminates the influences of target tissue anatomy and composition, ambient conditions and disease on the formation of the thermal lesion.

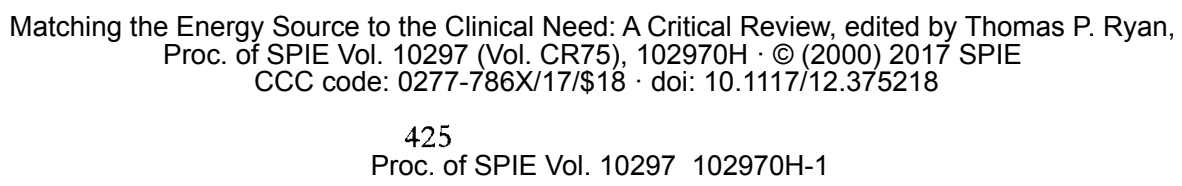




\section{Criteria for Qualitative and Quantitative Pathologic Evaluation}

Useful qualitative pathologic assessment of thermal lesions (or any pathologic lesion) requires 1) the identification of an abnormality and 2) a precise description of the abnormality relative to the surrounding tissues. Then, 3) the abnormality has to be proven to be due to the energy deposition and the subsequent generation of heat and not to artifact. Histologic artifacts resulting from poor fixation, rough tissue handling, and/or inadequate specimen processing have led to erroneous interpretations since many processing artifacts resemble thermal lesions.

Quantitative pathologic evaluation of thermal lesions encompasses all the criteria for qualitative pathology, but in addition, 4) the abnormality has to be measurable.

\section{THE PATIENT}

Each patient and her/his disease present a unique treatment problem that can change over time. Therefore, the patient's general health, location and extent of the disease, the functional anatomy at the disease treatment site and treatment goals have to be assessed for each person. There is no such thing as a generic "biologic tissue" just as there are no "normal biologic tissues or organs" that have static biologic and physical properties. Likewise, there is no generic "disease". For instance, a "tumor" in the breast could be a benign fibroadenoma, a cancer or an abscess due to infection.

\section{Anatomy and Tissue Composition .}

The cell with its nucleus and cytoplasm is the basic living unit. Tissues are complex assemblages of cells supported by extracellular matrix usually arranged in layers, nodules, masses and bands. Organs are composed of particular tissue types that have defined functions such as the bones for support, the heart to pump blood, the kidneys to maintain water, salt and nitrogen balance and the liver to metabolize many endogenous and exogenous substances. [10-14]

Tissues and organs are visually distinct because of their composition, color, function and boundaries. Likewise, the components of tissues and organs and their boundaries can be defined by other physical properties such as 1) elasticity, viscosity and density 2) electromagnetic conductivity and resistance, 3 ) heat transport and specific heat capacity and 4) mass.

Some tissues and organs such as the human liver or the thick subcutaneous adipose tissue of the sumo wrestler are sufficiently large to be considered as targets with semi-infinite boundaries. However, most animals and people parts are composed of closely packed 
layers with many well defined physical and physiologic boundaries. For example, the muscles of the legs and arms are composed primarily of skeletal muscle cells supported by a strong, relatively inelastic collagenous network. This network conveys the muscle contractile force to the rigid bones to produce work across the moveable joints. Muscle cell myoglobin and blood hemoglobin produce the distinctive red color of the muscle that contrasts with the light tan collagenous membranous coverings (fascia) that separate the individual muscle groups. The muscle cells and nerve conduct electrical currents to coordinate the extremity movements. The muscle groups are covered by a layer of fat tissue (subcutaneous tissue) whose thickness varies depending on the nutritional status, the habitus and sex of the individual. The subcutaneous tissue is covered by the distinctively layered skin composed of the vascular dermis and surface epithelium. The skin is important for temperature regulation, secretion of water, salts and $\mathrm{CO} 2$ and protection from desiccation and outside elements.

Then, to make things more complex, the anatomy and physiology of living organisms can change in response to age, sex, hormonal status, physical environment, metabolism, nutrition and reproduction. And, the organism is not even sick!

\section{Diseases}

The ancient Greek and Hindu physicians advocated cautery as a treatment of last resort after all their herbs, salves, prayers and incantations failed. [3-4]

"The diseases that medicine cannot cure, excision cures: those which excision cannot cure, are cured by the cautery; but those which the cautery cannot cure, may be deemed incurable." [15]

Nowadays, we can look at thermal cautery, cutting and coagulation as treatments for cure or palliation (relief of symptoms without total disease removal) depending on the disease process itself and the health status of the patient. The desired therapeutic goal of thermal medical applications is the modification or removal of a diseased part of the target tissue without creating undue harm to the surrounding normal tissues and to the patient himself.

\section{Thermal Treatment Criteria}

The diseases that are most amenable to ablative and coagulative thermal treatments are localized lesions in which the thermal treatments and their particular energy sources and instrumentation offer greater advantages than other available therapies. An excellent example is coagulation of detached retinas or retinal hemorrhages using laser light. This 
non-invasive, relatively cheap, outpatient procedure has stabilized the sight of thousands without requiring extensive eye surgery with its attendant morbidity.

New thermal treatments and new instrument development are being developed to exploit the advantages using minimally invasive surgical procedures. In particular, these procedures are beneficial for those patients who have other medical conditions that preclude major surgery, systemic chemotherapy of ionizing irradiation. The need to destroy isolated tumors such as uterine myomas (fibroids), metastatic cancers to the liver or lung or small primary breast cancers have led to development of new instruments for superficial and deep interstitial thermal coagulation. Superficial thermal fulgeration (ablation and coagulation) continues to be a useful approach for removal of superficial precancers and minimally invasive cancers of the larynx, uterine cervix and rectum.

Effective thermal treatments have to be designed paying strict attention to the anatomy, physiology and composition of the lesion as well as of the surrounding non-diseased tissue. Keeping this in mind, investigators are urged strongly to keep up-to-date anatomy, histology, pathology and physiology books on their desks. In addition, engineers and physicists should include motivated and interested pathologists, physiologists and clinicians on their lists of their closest and dearest collaborators.

\section{ENERGY SOURCES AND DELIVERY SYSTEMS}

The geometry of energy deposition in biologic tissues is determined by 1) the energy source itself, 2) the delivery systems, 3) the physical properties and anatomy of the tissues relative to the particular energy used and 4) continued energy delivery to the target tissue. The deposited energies are then transformed to heat by various mechanisms.

Once the heat is generated, the effective treatment geometry will depend also on the 5) thermal properties of the target, 6) the tissue temperature 7) time at temperature and 8) rate of desiccation. A useful maxim to remember is that, once generated, heat is heat.

\section{Laser Light:}

At the present time, therapeutic laser light irradiation is limited to the near-ultraviolet, visible and near-infrared wavelengths. Light energy is transformed to heat energy upon the light absorption by various tissue constituents. Therefore, the absorption, scattering and anisotropy of the target tissues and the delivery systems (air, fiber optics, wave guides, lenses, etc.) will be major determinants for energy deposition into a desired 
geometry. [16] The thermal lesion size and geometry can modified by using one or more irradiation beams directed to the target tissues using multiple lasers and/or multiple lenses, fiber optics or wave guides. Thus, the thermal lesion size and geometry can be refined by beam placement via the delivery system. The optical and thermal properties of the irradiated tissues usually change dynamically during the light exposure due to water loss and thermal tissue coagulation. [17]

\section{Radiofrequency Fields}

Radiofrequency electromagnetic fields (typically $500 \mathrm{kHz}$ to $500 \mathrm{MHz}$ ) are delivered to tissues by contact electrodes or antennas of various geometries to obtain useful current fields and heat lesion size. [1] Heat is generated as resistive dissipation (resistive or joule heating) due to collisions occurring during translational motion of charged carriers in the tissue located in the electric field. $[18,19]$ Therefore, the heat lesion will be greatly influenced by 1) the electrical properties of the tissue, 2) the use of monopolar vs bipolar electrode designs, 3) the current density, 4) the tissue anatomy and 5) tissue desiccation and thermal coagulation.

\section{Microwave Irradiation}

Microwaves ( $500 \mathrm{MHz}-5 \mathrm{GHz}$ and higher) produce heating by rotational motion of water molecule dipoles present in the tissue. [19] Like radiofrequency lesions, the thermal lesion produced by microwaves is markedly influenced by the configuration of the delivery antennas (wave guides) since heat generation occurs only in the electric field. Water is a major constituent of tissues, therefore heat generation will be dominated by the original tissue water content and the dynamic changes of water concentration due to vaporization during heating.

\section{Ultrasound}

Therapeutic ultrasound (typically $0.5-2.0 \mathrm{MHz}$ ) generates heat from viscous dissipation the acoustic waves propagating through biological tissues. $[18,20]$ Therefore, the tissue mechanical properties including the tissue viscosity, elasticity, specific heat and tissue density will be major factors in the production of thermal lesions. Tissue contact with the ultrasound probe and the probe configuration can also influence the lesion size. Ultrasound waves are easily scattered by the complex echogenic interfaces of tissues. Therefore, disease lesions close to the contact surface are most amenable to treatments using ultrasound energy sources. However, newer techniques of ultrasound focussing could allow deeper penetration for interstitial thermal treatments. Since piezoelectric probes can be fitted to flexible cables, the deeper cavities of the body can be accessed for diagnostic as well as therapeutic ultrasound applications. 
430 / Critical Reviews Vol. CR75

\section{Heat Transfer in Living Tissues}

The major determinant of heat transport in biological tissues is their water content (around $80 \%$ for soft tissues) therefore, their thermal properties will change as the tissue desiccates during the heating process. As desiccation continues on, the residual tissue constituents such as coagulated proteins, trapped vaporized water and melted fats will assume larger roles in heat transport. Convection heat loss is very important in living patients being treated by relatively low temperature (below $100^{\circ} \mathrm{C}$ ) and prolonged (seconds to hours) heat exposures. Convection heat transfer is produced by physiologic functions and environmental conditions. Blood and, to a lesser extent, lymph flow in vascular channels and air flow through the trachea and lung bronchi during respiration are the important intrinsic physiologic factors. Environmental causes of significant convection heat loss include 1) exposure of tissues to ambient air temperatures and room air circulation (operating rooms have significant air exchange volumes and are always too cold!), 2) irrigation of the surgical field, 3) exogenous organ perfusion such as the use of respirators or the heart-lung machines and 4) stoppage of blood and lymph flow as the blood and lymph vessels are tied off during surgery. [16]

\section{QUALITATIVE AND QUANTITATIVE PATHOLOGY OF ABLATION AND COAGULATION THERMAL LESIONS.}

The pathologic effects of thermal damage are numerous and, fortunately, are useful forto qualitative and quantitative analysis. Mapping and measuring the acute and healing thermal lesion are important factors in evaluating the treatment efficacy. [9]

The treatment goal for localized lesions such as cancers is to produce a lethal thermal damage volume that encompasses the tumor and a rim of surrounding normal tissue to coagulate peripheral microscopic disease. [Figure 1] Every effort should be made to identify local blood vessels, nerves, ducts, bronchi and vital organs so they can be excluded from the thermal lesion or, at least, be minimally damaged. For example, the pancreas and several large blood vessels supplying the intestines are adjacent to the liver hilum. Thermal damage to the pancreas during interstitial thremal therapy of liver tumors could lead to chemical pancreatitis as the damaged cells release their proteases and lipases. Thermal coagulation of the major vessels could lead to occlusive thrombosis with intestinal infarction, a potentially lethal complication. [13,21] 


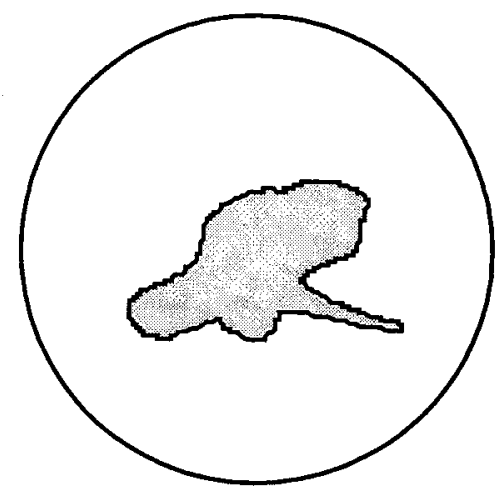

Figure 1

Configuration of Thermal Coagulation Lesion to Treat the Total Infiltrating Cancer

\section{Pathologic Markers of Thermal Damage in Biologic Tissues}

The geometric volume of energy deposition and heat transformation can be considered as a single volume heat source for most clinical thermal applications. As heat is transported along gradients from the hot center to the cooler periphery, concentric zones of thermal damage can be detected using gross and microscopic pathologic techniques. Likewise, a heat source slab placed on the target tissue surface creates layered thermal damage zones extending from the hotter surface to the cooler deep tissues. [Figure 2]

The boundaries between some of these zones can be distinct and measurable thus allowing mapping of thermal lesion. [9] These measurements also allow comparisons of different treatment effects, energy sources and instrument designs. Accurate comparisons require identification of useful treatment end points (markers) that can be measured and followed over time. In addition, pathologic observation techniques should be chosen that allow meaningful qualitative and quantitative evaluations of the treatment and its resolution. And, multiple experiments should be performed under the same controlled conditions using the same energy and delivery parameters to obtain statistically significant data.

\section{Thermal Damage Zones}

Beginning at the hotter center and progressing to the cooler periphery, the thermal damage zones can include 1) tissue ablation, 2) carbonization, 3) water-vaporization 


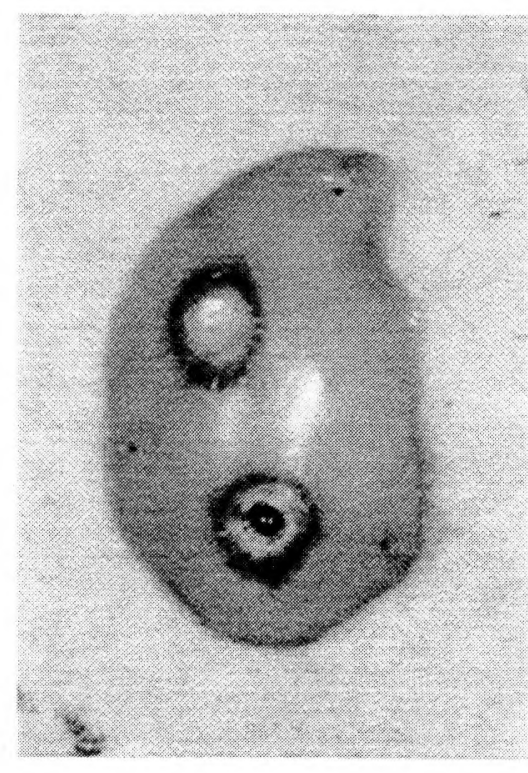

A

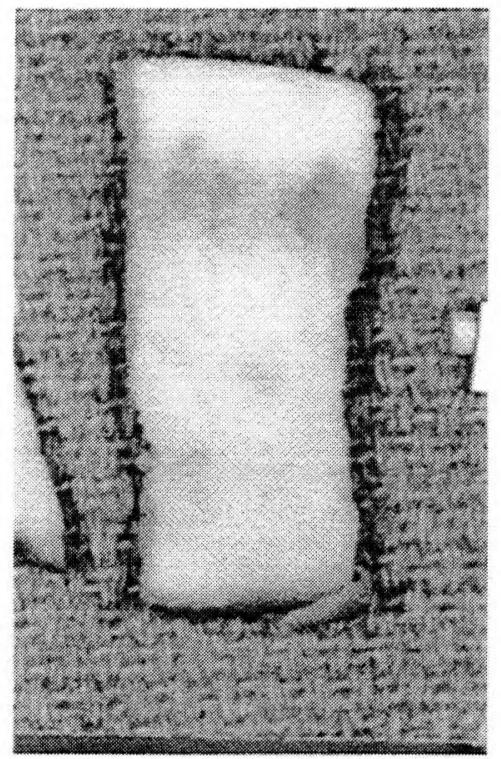

B

Figure 2

Thermal ablation and coagulation lesions: Examples of single volume heat source and slab heat source lesions.

A. Coagulation (upper) and coagulation/thermal lesions were produced in vivo in rats and the liver harvested 30 minutes after treatment using a CW $\mathrm{Nd}$ :Y laser. The concentric zones of thermal damage extend from the center point of light irradiation which in these lesions are represented by the white central coagulum (structural protein thermal coagulation) in the upper lesion and the dark hole in the lower lesion.

B. A flat heat source (water-filled balloon) was expanded within the uterus cavity of a woman undergoing hysterectomy. The blood supply was cut off and the uterus was removed about 30 minutes after heating. The thermal damage zones, surface white coagulum and subjacent red damage zone have distinct, measurable borders. 
thermal damage including steam vacuole formation, explosive fragmentation and tissue desiccation, 4) structural protein denaturation (thermal coagulation) including collagen hyalinization, collagen and muscle birefringence changes, tissue whitening and cell shrinkage, 5) vital enzyme protein denaturation, 6) hemorrhage, hemostasis and hyperhemia, 7) tissue necrosis and 8) wound organization and healing. Some of these zones can be seen during and immediately after heating in vitro or in vivo applications but others can only develop in the living and surviving subject. [Table 1]

Table 1

Thermal Damage Zones

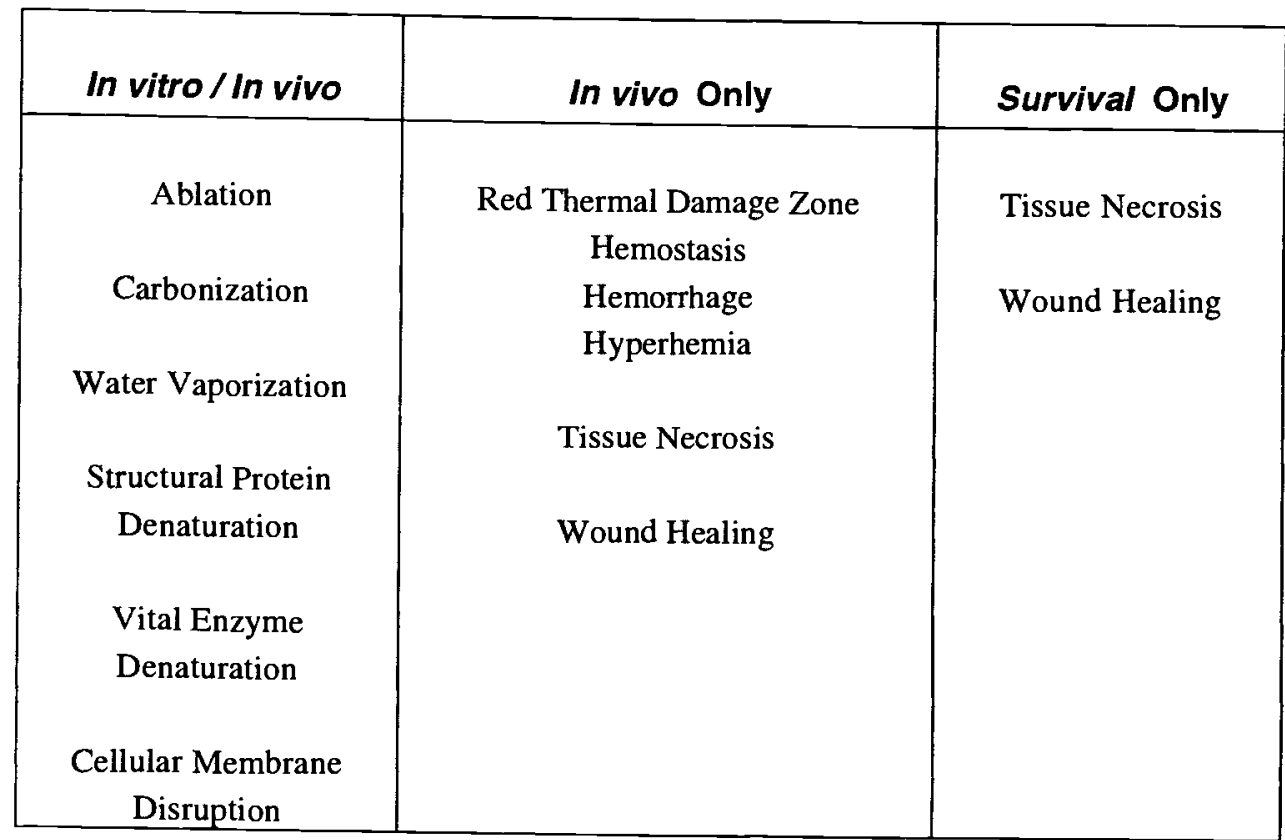

\section{Ablation:}

We have arbitrarily defined ablation to be the physical removal of the solid components of tissue. Chunks, fragments, layers, cells, molecules and ionized atoms can be removed from tissue depending on the energy delivered in each exposure. In the realm of current thermal therapies, holes, defects, craters or cuts can be produced by any or all of the following 1) thermal tissue vaporization, 2) combustion and/or 3) explosive fragmentation. [Figure 3] 

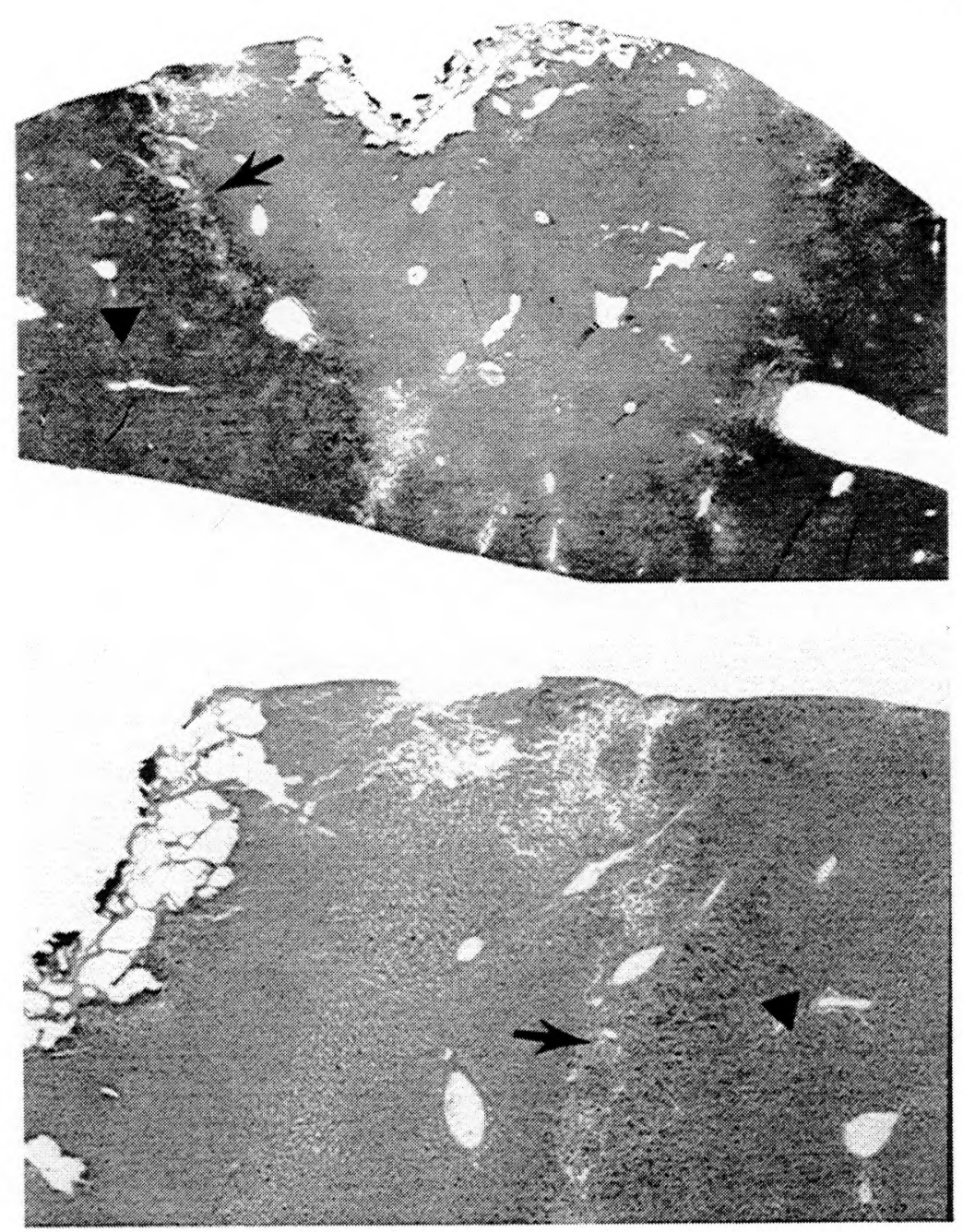

Figure 3

Thermal ablation and coagulation lesion in rat liver produced with $\mathrm{CW}$ argon laser 9W, 9Sec, Spot Size $1 \mathrm{~mm}$. The central ablation hole is lined by scattered black carbon granules covering the subjacent vacuolated water vapor damage zone. Beyond this zone, the structural protein coagulation zone extends to the inner boundary of the red damage zone (arrows). The outer boundary of the red damage zone (arrow heads) is faint in this black and white image. The lower picture is a higher magnification of the upper image. [H\&E. Original Mag. 3X and 8X] 


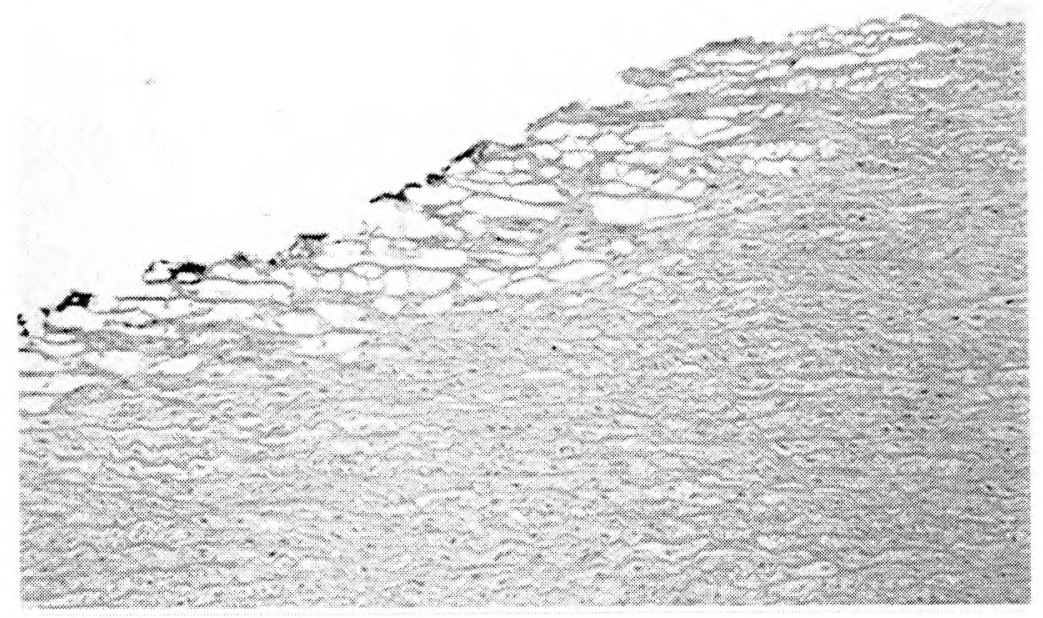

Figure 4

Part of thermal ablation hole and water vapor damage zone in dog aorta. Irregular black carbon granules are scattered on the surface of the lesion. The water vapor (steam) vacuoles form a distinct zone with a measurable boundary. The structural protein thermal coagulation damage is not visible at this magnification. [H\&E. Original Mag. 25X] 


\section{Carbonization:}

Carbonization is the thermal reduction of organic tissue components to carbon. In ablation lesions, the black granular carbon residues $(<1$ to $10-\mu \mathrm{m})$ form a thin lining of the ablation site. Although this layer can be measured microscopically, the actual identification of carbon formation probably is more important than the measurements when evaluating dosimetry and/or instrument design. Carbon formation is undesirable in laser interstitial thermal therapy as the carbon absorbs the incident light preventing its transport into the surrounding tissues. In addition, carbonization can signal unwanted arcing across electrodes or tissue combustion. [Figures $3 \& 4$ ]

\section{Water Vaporization:}

Nearly all biological animal tissues contain about $80 \%$ water (except bone, tooth enamel and dentine, finger and toe nails, hair and the outer layer of the skin, the stratum corneum). Water is always sublimating from tissue surfaces and, as the tissue temperature increases, more water vaporizes. At temperatures below $100^{\circ} \mathrm{C}$, water vapor formed close to the surface usually can diffuse out of the tissue. But, as the temperature approaches and passes $100^{\circ} \mathrm{C}$, water vapor (steam) formation accelerates. The amount of steam formed is greater than that which can escape from the tissue by diffusion. Therefore, small vapor pockets form within the tissue and grow bigger as the superheated steam rapidly expands, the so-called "popcorn" effect. The thin, desiccated, rigid walls of the vacuoles rupture as the vapor pressure increases allowing the vacuoles to form larger steam pockets deeper in the tissues. But, closer the surface, the rapidly expanding pockets burst open blowing tissue fragments into the air thus producing an ablation cavity with tissue mass loss due to explosive fragmentation. [Figure 3]

Not infrequently, the zone of water vacuolization has a fairly distinct, measurable border. [Figure 4] However, depending on the tissue anatomy and its mechanical properties, the vapor can dissect along weak planes to form a recognizable, but not measurable, thermal damage zone.

The problem of distinguishing true water vacuoles from fixation or tissue processing artifact in microscopic sections can be difficult in certain tissues. For example, slit-like spaces are frequent in light microscopic sections of arteries and cornea. These artifacts are due to uneven shrinkage and contraction of collagen layers produced by fixation and heat applied during the preparation of the tissues for paraffin sectioning. Thermal vacuoles can be distinguished from histologic artifact by the following observations: 1) heat lesion vacuoles will be clustered and more numerous in the lesion than in the surrounding tissue, 2) the lesion vacuoles will have some regular distribution reflecting the geometry of energy deposition and heat transport and 3) other signs of thermal 
damage such as collagen hyalinization and birefringence changes will be associated with the vacuoles. Of course, the knowledge that a thermal lesion was made in the location under observation is an additional diagnostic bonus.

\section{Structural Protein Thermal Coagulation (Denaturation)}

Structural proteins are the proteins that form the extracellular matrix and cytoskeleton of all cells. The formed extracellular structural proteins such as the collagens and elastins form the dermis, tendons and general fibrous supporting structures of all tissues. These formed elements are intimately related to various proteoglycans that generally act as an amorphous matrix that binds considerable amounts of water. The cytoskeleton structural proteins are the microtubules, microfilaments and intermediate filaments that form 1) the three-dimensional scaffolding of the cytoplasm and nucleus, 2) the contractile proteins of the muscle cells, 3) the mitotic spindles and 4) intracellular and extracellular communication transport networks. [10, 11, 14, 22,23]

Grossly, most thermally coagulated tissues become lighter colored and more opaque as is seen when red steak is boiled and eggs are fried. Cooked meat and egg whites are good examples of protein thermal coagulation. On the other hand, fat (adipose) tissues and collagen-rich tissues such as tendon and sclera become more translucent with heating. The pale borders of thermally coagulated tissue are usually measurable grossly.

Microscopically, within the coagulum, there are several concentric thermal damage zones with distinct boundaries that can be measured. Beginning from the hotter center and going to the cooler periphery these zones include 1) collagen (Type 1) denaturation manifest by birefringence changes and hyalinization, 2) muscle cell birefringence changes and 3) cell shrinkage. All of these changes are due to thermal denaturation of structural proteins.

Collagen and Muscle Birefringence Changes,

Native Type 1 fibrillar collagen is composed of macromolecules arranged in a semicrystalline array which is responsible for the formation of a bright birefringent image when observed with polarizing light microscopy. $[10,11,23-26$,] In addition, the $\alpha$ helical arrangements of the polypeptide molecules that form the basic collagen molecule, tropocollagen, confer birefringence intrinsic to the molecule. In a similar fashion, the contractile proteins of skeletal, cardiac and smooth muscle are also brightly birefringent. Roughly, $80 \%$ of the collagen and muscle birefringence is form birefringence due to the crystalline array of the macromolecules while the rest is the intrinsic molecular birefringence. [Figures $5 \& 6$ ] 

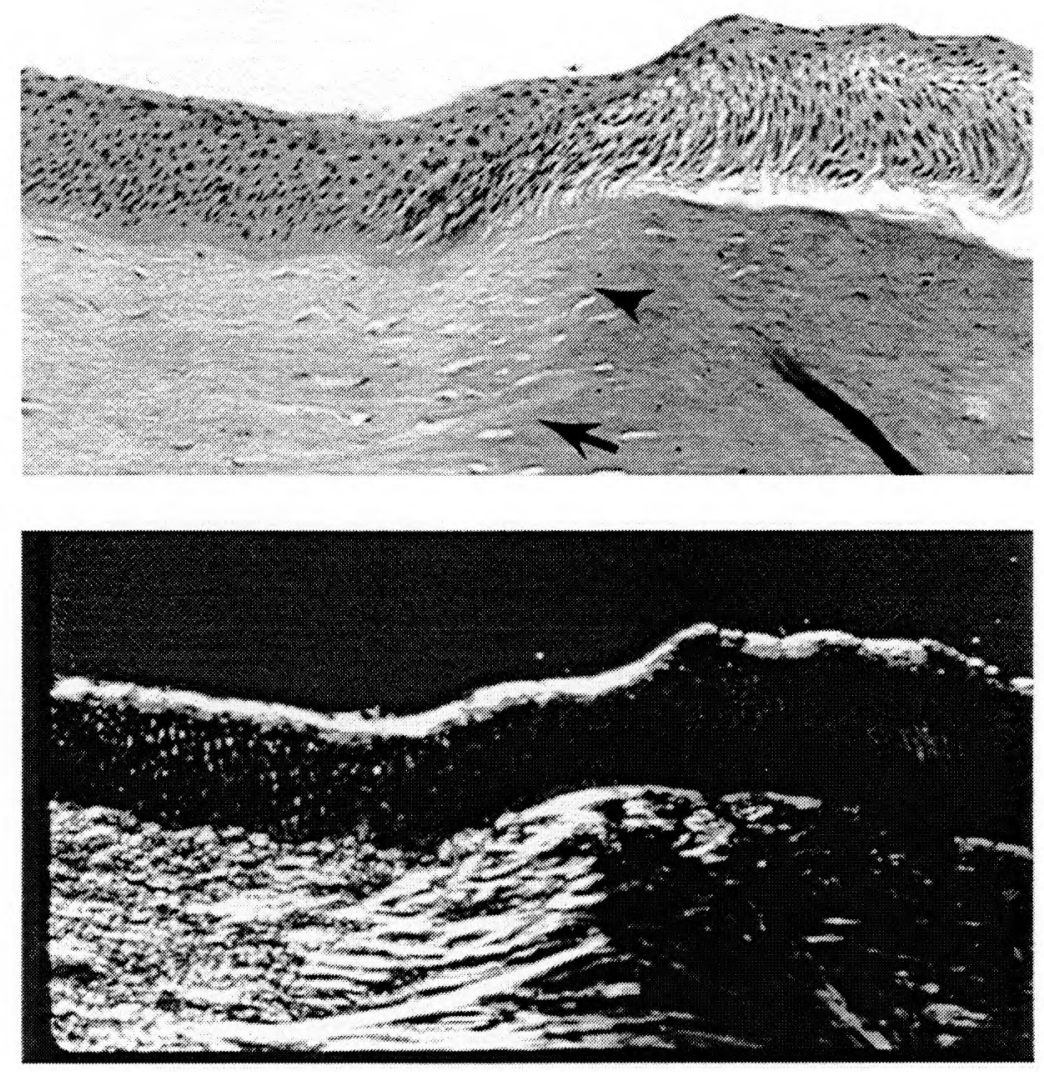

Figure 5

Thermal coagulation lesion in pig cornea in vtro.

Several structural protein thermal coagulation changes can be seen in the routine $H \& E$ stained paraffin section examined through a diffuse light microscope (upper) and a transmission polarizing microscope (lower). Thermally induced collagen hyalinization (upper right) forms a dark, amorphous area with a distinct boundary (arrows). In this case, the boundary of partial birefringence loss coincides with that of hyalinization. The characteristic fibrous profiles of native collagen (left) are well illustrated in the TPM image. The corneal epithelial cells covering the coagulated collagen are spindled due to thermal denaturation of their cytoskeletons. The continuous bright white line in the TPM is a drying artifact of the epithelial surface. (H\&E. Org. Mag. 40X) 

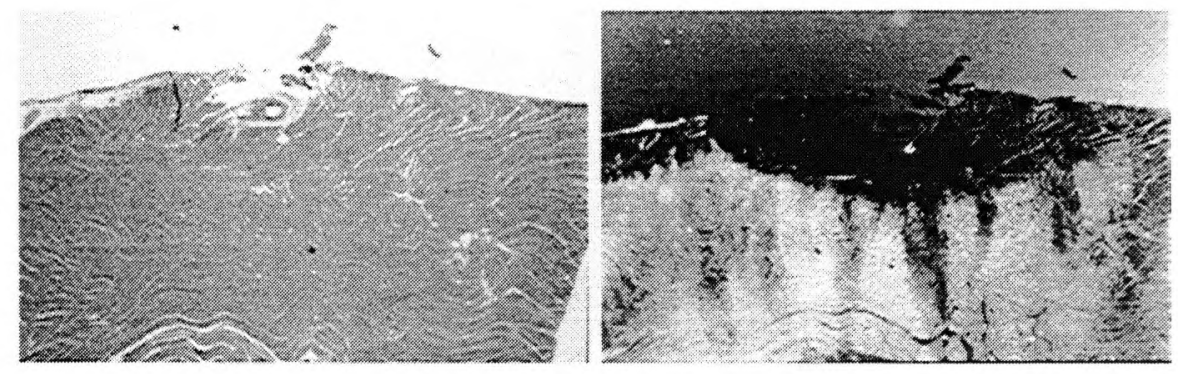

A

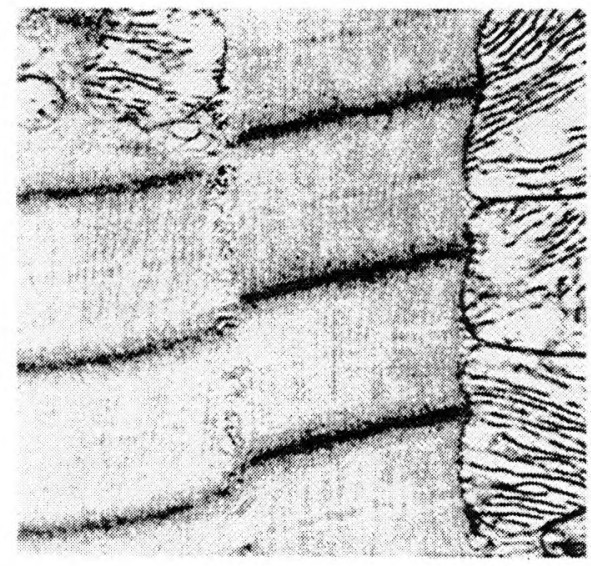

C
B

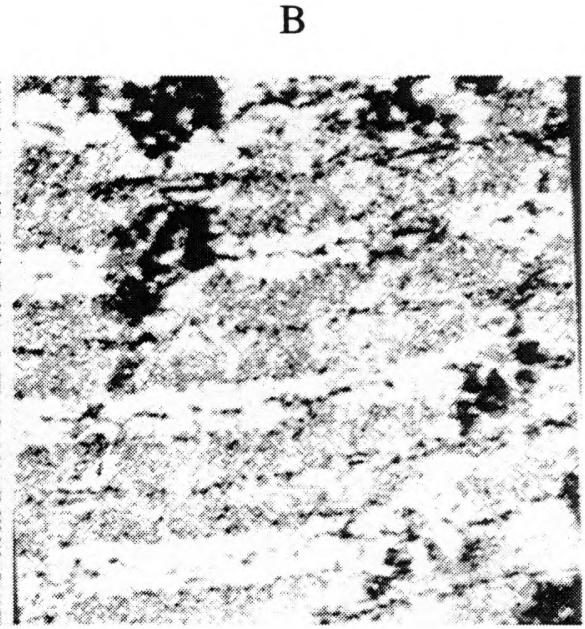

$\mathrm{D}$

Figure 6

Birefringence Loss in Thermal Ablation/Coagulation in Rabbit Heart

Structural protein thermal coagulation is not apparent in the light microscopic image of heart muscle (A) but the boundary of birefringence image intensity loss (B) in the TPM of the same field is definite. Transmission electron microscopy of the native heart muscle $(C)$ reveals the normal semicrystalline array of the fibrillar contractile proteins and the layered membranes of the mitochondria. In the thermally coagulated area of birefringence loss (D), the contractile proteins are dissociated and the mitochondria have been reduced to relatively large dark globules with no internal structure. [A and B. H\&E. Org. Mag. 12.5X. C and D. Uranyl acetate and lead citrate stains. Org. Mag. About 15,000X] 
Thermal denaturation of the collagen and muscle proteins disrupts their crystalline arrays and tertiary molecular structures leading to a loss of their birefringent properties. [Figure 6 and ref. 24]

Depending on the temperature and time of heating, different zones of partial and complete birefringence loss of collagen can be seen and their boundaries measured. The birefringence changes of the proteins that form the contractile elements of muscle cells occur at slightly lower temperatures. The boundary of collagen birefringence loss is closer to the hot heat source than that of muscle loss. Therefore, if the target tissue contains muscle and collagen and the heating is relatively slow (several seconds to few minutes), four different boundaries of total and partial birefringence loss can be potentially identified and measured.

The development of the thermal damage end point of total birefringence loss observed in stained paraffin sections using the transmission light microscope (TPM) is related exponentially to temperature and linearly to time. $[24,27-30]$ In this case, the endpoint is precisely defined, total loss of the birefringent image as observed at the magnification levels offered by the TPM in tissues heated at constant temperatures over several minutes. The first-order kinetics of this specific change from native to thermally denatured collagen do not consider the numerous intervening episodes of chemical bond breakages that occur before the desired end point, birefringence intensity loss is obtained.

Transmission electron microscopy (TEM) of totally hyalinized and partialy and totally non-birefringent collagen tissue give some idea of the numerous dissociation processes that are taking place. In areas of total hyalinization and birefringence loss, TEM shows monotonous fields of small granules in stained plastic sections. The granules probably represent totally dissociated collagen molecules that have lost their linear and macromolecular structure. Some of the granules may also represent other denatured extracellular matrix proteins and proteoglycans. In areas of partial birefringence, TEM shows varying degrees of collagen macromolecular dissociation with disruption of the crystalline linear array of the macromolecules. As the dissociation and birefringence loss becomes more prominent, more granules appear mixed with the more loosely formed macromolecules.

There are many types of collagens and not all are birefringent when observed with the polarizing microscope. $[10,11]$ Some collagen fibers are thin and loosely distributed in tissues thus are difficult to see. Sometimes, certain stains such as Sirius red can enhance their birefringence. However, the thermally induced birefringence changes cannot be distinguished easily with this stain. Other collagens have a netlike macromolecular configuration formed of non-fibrillar collagen molecules therefore are not birefringent. 


\section{Collagen Hyalinization:}

The thermal dissociation of collagen macromolecules changes the native collagen fiber to a swollen, amorphous, fiber as observed through a light microscope. With prolonged heating or higher temperatures, the thermal denaturation of collagen is advanced and what was once a felt work of distinctive fibers is now a continuous glassy (hyalinized) field of denatured protein. Not infrequently, the boundary between the native and hyalinized collagen is distinct and measurable. [Figure 5] But, the distinction becomes blurred in tissues formed of densely packed, thick collagen fibers such as dog connective tissue.

\section{Cytoskeleton:}

The three-dimensional shape and size of all cells depends on a meshwork of microtubules, microfibrils and intermediate filaments made of a variety of proteins. [10, $22,23]$ When thermally denatured, the cytoskeleton dissociates and, generally, the cells become elongate and flattened. Not infrequently, cellular desiccation occurs at the same time leading to additional cell shrinkage and consolidation of intracellular proteins reflected by the increased color intensity (hyperchromasia) of the cytoplasm and nuclei in hematoxylin and eosin (H\&E) stained sections. The nucleus has its own protein skeleton that is equally susceptible to thermal denaturation and collapse leading to chromosomal consolidation.

Epithelial cells that form the linings and surfaces of many organs and tissues, such as epidermis, glands, gastrointestinal mucosae, urinary bladder and many others, tend to elongate from their normal cuboidal or columnar shapes to form thin spindled cells when heated. This epithelial spindling forms a distinct thermal damage boundary that can be quire useful for mapping of thermal lesions in the breast, prostate and corneal epithelium. [Figure 5]

Easily recognizable spindling or cell shrinkage does not occur in the more solid epithelial organs such as the liver and kidney. Thermally coagulated cells in these solid organs can appear amazingly intact in routinely stained paraffin sections examined at the light microscopic level. Yet, at the higher magnifications of TEM, the organelles are disrupted and granules of denatured proteins, DNA and mitochrondria are precipitated within the cell. Some reports of liver interstitial coagulation have described cells in the coagulum center as looking "viable" when, indeed, they are not. It is of interest that, in the $19^{\text {th }}$ century, anatomists would "fix" tissues for histologic examination by boiling them. 


\section{Vital Enzyme Denaturation and Cellular Membrane Dissociation}

The thermal denaturation of the enzymes required for basic life processes is similar to that of the structural proteins but occurs at lower temperatures and heating times than structural protein coagulation. Therefore, these lethal effects occur beyond the zones described above and are found at the periphery of the lesion.

Several of the vital enzymes, if still functional, can reduce certain dyes to colored products thus supposedly demarcate viable from non-viable tissues. [31-33] However, in very acute lesions, some cells may be severly damaged nigh onto death but their enzymes will continue to work for awhile. Therefore, the colored ("viable") / noncolored("dead") boundary may be distinct but not show the ultimate lethal thermal damage boundary. Vital staining can be useful for comparisons of lesion extent or size but cannot be relied upon to indicate the ultimate extent of cell death and effective treatment.

Membrane Damage:

The membranes of cells and cellular organelles are complicated layers of hydrophobic and hydrophilic lipoproteins forming the boundaries between the interiors and exteriors of these structures. [23] Cellular membranes are dynamic structures behaving like a constantly changing fluid interface containing pores and binding sites that require chemical energy to function. In addition, the membranes separate electrical, ionic and molecular gradients that are critical components of everyday living. [10,11]

It is apparent that major disruption of the cellular membranes could be and is a catastrophic event leading to inevitable cell death. On the other hand, minor disruptions can be and are quickly repaired allowing the cell or organelle to survive. Cellular membrane disruptions can be detected by TEM (mainly in cases of major disruption) but minor damage is best detected by either electrophysiological or molecular techniques. Practically speaking, the tedious demarcation of a thermal damage zone of cellular membrane damage is not useful for testing the efficacy of clinical thermal treatments. If cell deathis due to membrane damage, then the only efficient way to detect the damage is to let the target animal survive until all cells that are going to die have died and have undergone necrosis.

\section{THERMAL DAMAGE ZONES DETECT ABLE ONLY IN VIVO AND/OR IN SURVIVING SUBJECTS.}

So far the thermal damage zones have been discussed are those that can be seen in lesions produced in vitro or in vivo without survival. However, other markers of thermal damage 
can only be detected in living and/or surviving subjects. These include 1) a grossly apparent red thermal damage zone that is peripheral to the central white coagulation zone, 2) tissue necrosis and 3 ) wound healing.

\section{Red Thermal Damage Zone}

A grossly apparent red band or zone develops within 30 seconds to 2-3 minutes just peripheral to the central white coagulation zone in thermal lesions produced in living organs with an intact blood supply. This red zone forms as a consequence of thermal damage to blood vessels and a complex series of physiological vascular responses to heating that produce 1) hemostasis (blood flow stasis), 2) hemorrhage and 3) hyperhemia (increase blood flow). The three pathologic changes are intermixed and do not form distinct microscopic zones within the red zone but hemostasis tends to be closer to the white coagulum and the hemorrhage and hyperhemia are more peripheral. $[20,24,26-$ 30]

The hemostasis is a result of direct thermal coagulation of red blood cells with small blood vessels stopping blood flow. Hemorrhage, the escape of blood from thermally damaged blood vessels, requires flow of incoming blood with a pressure gradient that pushes the blood in the surround tissues. Increased blood flow produced by local release of vasoactive substances that stimulate dilatation of small blood vessel is a classic vascular reaction to increased temperature of time. [20, 28, 29] This response is familiar to anyone who has burned his hand while cooking. The vasoactive response has been shown to be exponentially related to temperature and linearly to time at temperature. 1 , 27-30]

If the single heat source energy delivery remains constant, then the red thermal damage zone stabilizes and stops growing because of the equilibrium established between heat generation and convection heat loss due to blood flow. [17] The red thermal damage zone persists for various intervals due differences of mechanisms of resolution, the organ site and the species. [Table II]

\section{Necrosis:}

The full extent of lethal thermal damage cannot be determined until all injured cells that are going to die are dead and undergo necrosis. Depending on the mammalian species and the tissue, the full extent of lethal thermal damage as revealed by necrosis takes from 1 to 5 days to develop. There are four general mechanisms of necrosis in thermal lesions. Thermal coagulative necrosis occurs immediately upon heating. Heat-related lytic necrosis, ischemic necrosis and apoptosis. are delayed responses to lethal thermal injury. $[14,20]$ 


\section{Table II}

\section{Red Thermal Damage Zone Resolution Intervals}

\begin{tabular}{|l|l|l|}
\hline Animal \& Tissue & \multicolumn{1}{|c|}{ Interval (days) } & Mechanism of Resolution \\
\hline Goat Breast & 13 & $\begin{array}{l}\text { 1) Slough Of Necrotic Tissue Into Large } \\
\text { Breast Ducts } \\
\text { 2)Organization and Scar Tissue } \\
\text { Replacement of Necrotic Tissue }\end{array}$ \\
\hline Pig Lung & $7+$ & $\begin{array}{l}\text { Organization and Scar Tissue } \\
\text { Replacement of Necrotic Tissue }\end{array}$ \\
\hline $\begin{array}{c}\text { Pig Skin } \\
\text { Back }\end{array}$ & 21 & Eschar (Scab) Formation And Slough \\
Belly & 11 & Eschar Formation And Slough \\
\hline Rat Skin & 5 & Necrosis \\
\hline Rat Liver & 3 & \\
\hline
\end{tabular}

Thermal Coagulative Necrosis:

Thermal coagulative necrosis is due to the direct thermal coagulation of structural proteins and vital enzymes. Therefore, the cells and tissues in the central coagulum are dead immediately upon treatment. The coagulated cells cannot undergo cell disintegration since their lytic enzymes, the proteases and lipases, have been thermally denatured. The central coagulum will persist in the thermal lesion until blood flow and wound healing processes bring in viable inflammatory cells to organize the coagulum. [Thomsen, Unpublished observations]

Heat-related Lytic Necrosis:

Heat-related lytic necrosis results from the low-temperature thermal rupture of cellular organelles releasing lytic enzymes that digest the tissues. Also, lytic necrosis is produced by inflammatory cells that release their proteases and lipases to produce further necrosis.

Ischemic Necrosis:

Ischemic necrosis results from blockage of blood flow due to occlusive intravascular thrombosis in thermally damaged blood vessels and/or thermally induced hemostasis. The blockage leads to ischemia in the downstream tissues leading to regional tissue death. The organelles, particularly the lysosomes, of ischemic cells undergo membrane rupture and release of lytic enzymes that produce lytic necrosis. Ischemia also initiates a 


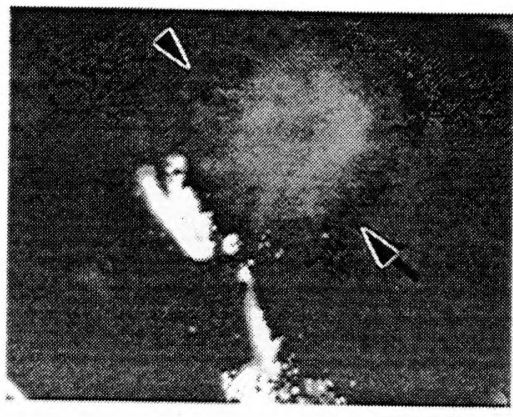

Acute

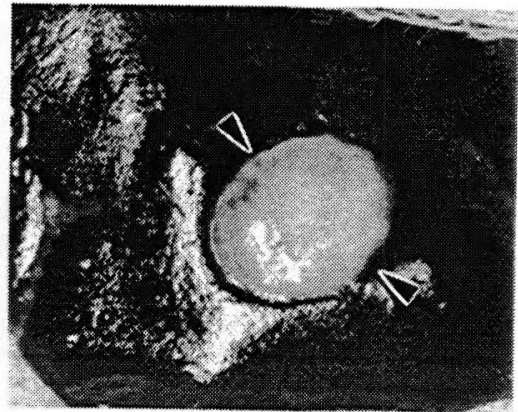

3 Days

\section{Red Zone Diameter vs Necrosis Diameter}

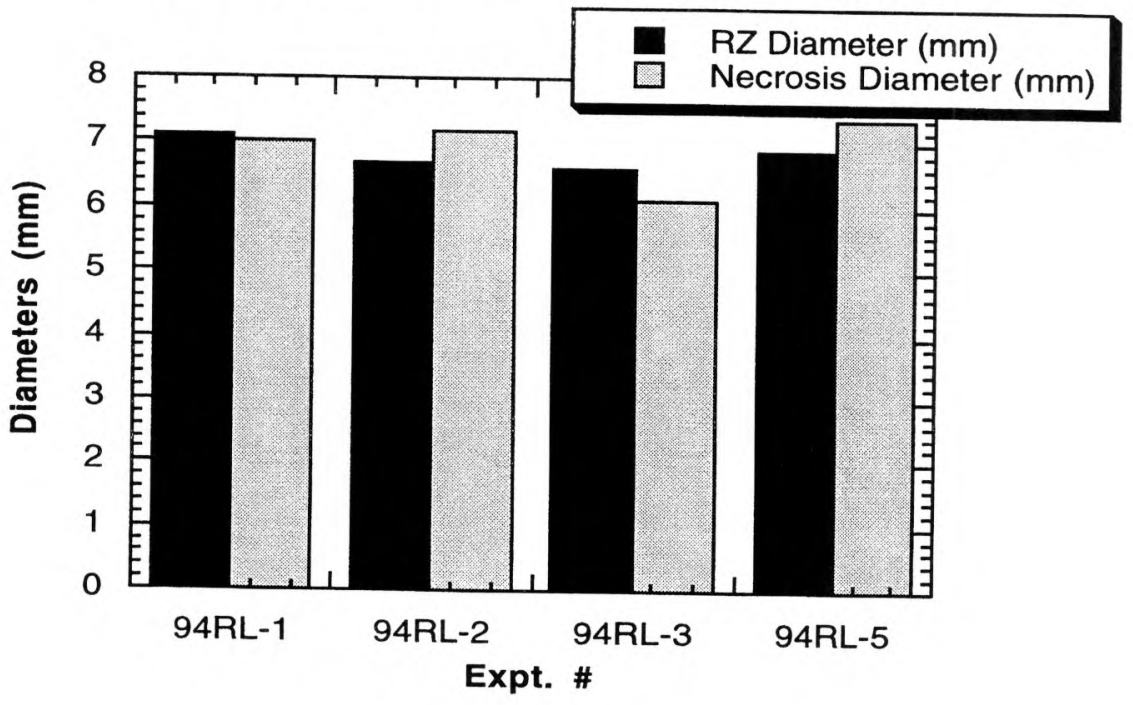

Figure 7

Thermal Coagulation Lesions in Rat Liver: Comparisions of Diameters of Outer Boundary of Red Zone in the Acute Lesions and Necrosis at Three Days.

The outer boundary (arrows) of the red thermal damage zone in the acute lesion and the boundary (arrows) of necrosis are the same as shown in the graph. The measurements were made in the same surviving animals at the time of treatment (red zone) and at time of maximal necrosis at three days. The liver photos are of rat 94RL-3. 
446 / Critical Reviews Vol. CR75

series of inflammatory and vascular responses that bring in inflammatory cells and their lytic enzymes.

The cellular mechanisms of heat-induced and ischemic lytic necrosis are the same but the primary causes are different and predominance of either mechanism varies among different organs and tissue sites. Ischemic processes with occlusive vascular thrombosis are prominent in the resolution of thermal intersitial lesions in pig lung while lytic processes are more prominent in the organization and healing of goat breast coagulation lesions. [Thomsen. Unpublished observations]

Apoptosis:

On the other hand, apoptosis (programmed cell death) is an entirely different mode of cell death that usually occurs within 24 hours of treatment. Heat as well as several other chemical, biological and physical insults can trigger apoptosis, a series of energyrequiring events leading to cellular and nuclear fragmentation and death in specifically genetically programmed cells. Not all cells can undergo apoptosis. Endothelial cells, lymphocytes and some tumor cells can show the characteristic apoptotic degenerative changes at the periphery of thermal lesions around 24 hours after heating. Apoptosis is a phenomenon initiated in living cells therefore apoptosis will not be seen in the central thermal coagulum nor later than 24-36 hours unless there is further insult to still viable cells in the periphery. [Cotran]

The outer boundary of the red thermal damage zone corresponds to the boundary of tissue necrosis in thermal lesions of several organs including rat liver, goat breast, pig lung and human endometrium and myometrium. [Figure 7 and ref. 34] Therefore, the red zone can be used to predict the full extent of treatment effect in some thermal coagulation lesions. However, the necrosis and scarring can extent beyond the thermal lesion when occlusive thrombosis and regional ischemia occur. In this case, the treatment effect will involve not only the thermal lesion but also the tissue downstream from the blockage. The ischemia can result in infarction, or, in the case of the pig lung, collapse and chronic fibrosis of functioning lung tissue.

\section{Wound Healing}

Wound healing involves a series of steps that can be divided into three general categories: 1) organization of the necrotic debris, 2) tissue regeneration and 3) scar formation and contraction. [20,35] 


\section{Organization:}

The necrotic tissue needs to be removed before wound healing can be completed. The numerous interrelated cellular, vascular, inflammatory, immune and hormonal processes involved in the organization of necrotic tissue are far too complicated to detail in this chapter. However, the bottom line of organization is that the necrotic tissue has to be broken into manageable components to be removed before healing takes place. Initially, infiltrates of inflammatory cells, particularly polymorphonuclear white blood cells, rally to the injured tissue not only to contribute to the necrosis process but also to continue the lytic breakdown of the necrotic debris. The smaller molecular components are released into the circulation and removed or recycled in various organs of the body. The larger components are literally "eaten up" (phagocytosed) by cells (macrophages) whose major function is to be the garbage handlers of the body.

Depending on the species and organ, thermal lesion organization begins from one day (rat skin), to two to three days (pig skin and goat breast) to three to five days (pig lung) after treatment. The organization originates from the peripheral viable tissues and progresses into the lesion. In hollow organs such as the gut, pulmonary bronchi and urinary bladder, the necrotic tissue is sloughed into the organ lumens and eventually evacuated from the body. In solid organs, the necrotic tissue remains in the thermal lesion until removed by macrophages or replaced by regenerating tissues or scar tissue processes that can take weeks. Skin lesions are exposed to air so the necrotic tissue dries forming a scab (eschar). As the tissue demolition and removal take place, several chemical and hormonal factors are being produced to signal the initiation of tissue regeneration and scar formation.

\section{Tissue Regeneration:}

After lethal injury, no matter what the cause, some tissue such as the epidermis of skin can totally regenerate. On the other hand, some tissues such as liver and breast ducts can partially regenerate and other tissues such as heart and nerve tissues never regenerate. Therefore, depending on the tissue type, wound healing of thermal lesions will resolve by tissue regeneration and/or scar formation. In most tissues, the thermal lesions are sufficiently large that scar tissue formation is predominant.

Tissue regeneration is initiated by production of various growth factors including many types of epithelial growth factors that stimulate proliferation and differentiation of new tissue (parenchymal) cells. Vascular and fibroblast growth factors stimulate new blood vessel growth, fibroblast proliferation and collagen formation to feed and support the functioning regenerated epithelial tissue. 
Scar Tissue Formation:

Depending on the size of the thermal lesions and the general physiology of the tissue/organ, the rate of vascular and fibroblast proliferation can be greater than the rate of tissue regeneration. This proliferation leads to the formation of vascular and fibrous granulation tissue, the early forms of scar tissue. Granulation tissue originates form the peripheral viable tissues and invades into the necrotic tissues hard on the tail of the organization processes. Depending on the lesion size and vascularity of the host organ, complete replacement of the necrotic tissue can take several weeks to months.

New scar tissue tends to be very vascular and formed of loose collagenous fibers and bands. However, as the scar ages, many blood vessels are resorbed, the collagen fibers become larger and more densely packed and the entire scar shrinks. Scar tissue is usually pale tan reflecting its collagen content and can be readily distinguished from surrounding tissues. However, as the scar ages and contracts, the boundary between the scar and normal tissue can become obscured particularly in normally pale tissues such as breast. [Figure 8] Then, microscopic evaluation sometimes with the use of special stains will be needed to discover the thermal lesion. It is to be remembered that most thermal lesions used to treat symptomatic diseases are too large to be replaced by the original tissue. The scar will always be there no matter how small.

\section{PRACTICAL GUIDELINES FOR PREPARING THERMAL LESIONS FOR PATHOLOGIC EVALUATION}

The pathologic techniques and markers of thermal damage described above provide several tools to 1) map extent and configuration or interstitial or surface thermal lesions, 2) make comparisons of experimental parameters such as using different instruments, energy sources, feedback systems, etc. and 3) treatment effects.

Proper dissection and preparation of the thermal lesions and the surrounding tissues requires careful planning and consultation with the pathologist who will be evaluating the pathologic specimens. Animal experiments and histopathology are the two most expensive portions of the usual experimental budget. Therefore, to avoid expensive and wasteful duplications and repeats, the investigator(s) are urged to consider their experimental goals before doing the treatments.

\section{Choosing the Right Marker and the Right Tissue}

Comparisons require choosing markers that are measurable and reliably reproducible in the target tissue. The marker(s) should be relevant to your experimental goals. For example, comparisons of treatment effects require choosing markers that indicate the full 


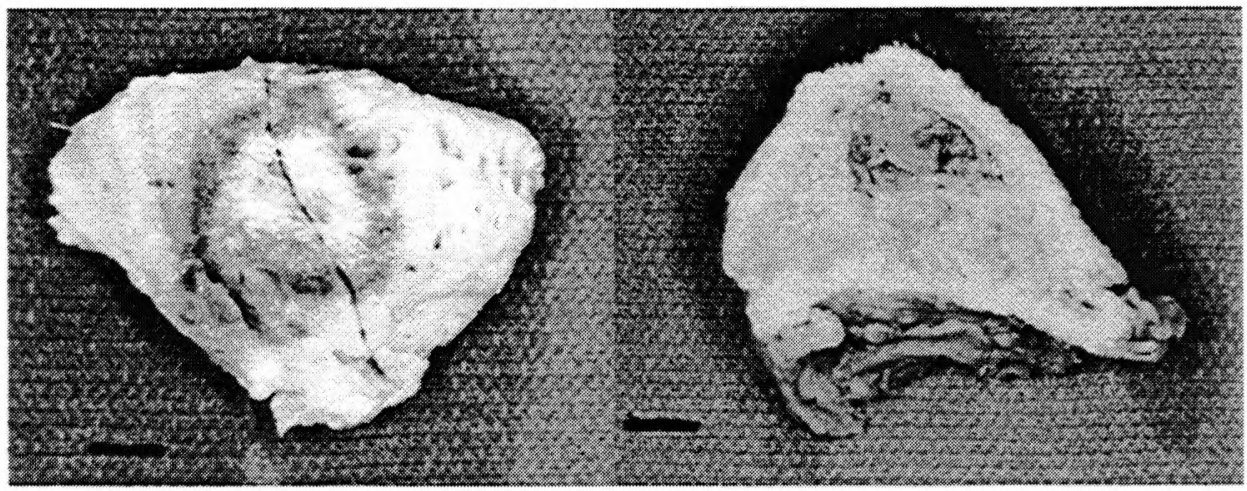

Acute

13 Days

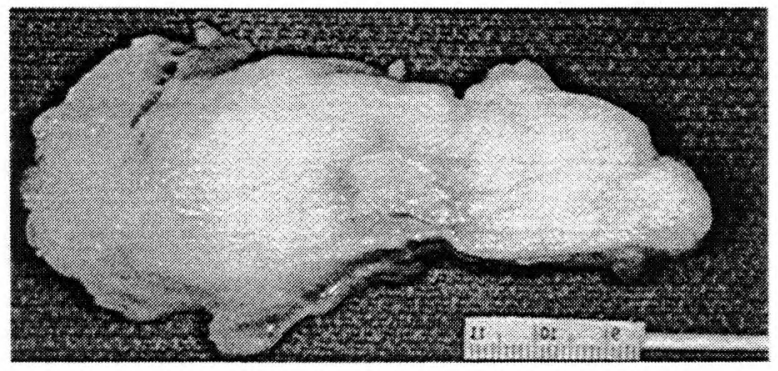

84 Days

Figure 8

Healing Thermal Interstitial Coagulation Lesions in Goat Breast.

The red thermal damage zone is prominent in the acute lesion. The red zone as been replaced by scar tissue at 13 days however the central darker coagulum remains. At 84 days, the pale residual coagulum (necrotic fat) is outlined by the slightly darker fibrous scar tissue. The bars equal $1 \mathrm{~cm}$. 
450 / Critical Reviews Vol. CR75

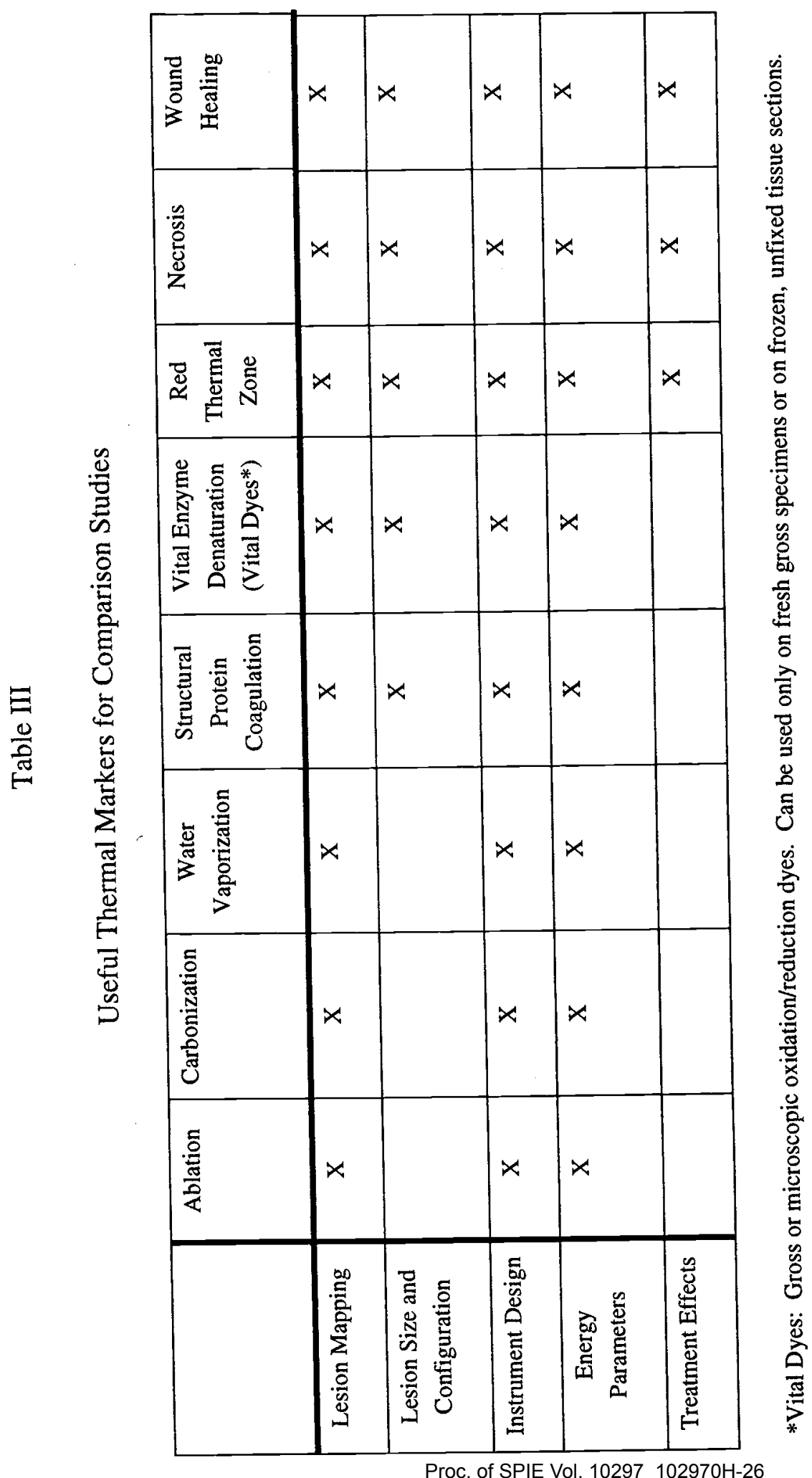


extent of lethal thermal damage such as necrosis and wound healing in survival animals. On the other hand, comparisons of different experimental parameters or instruments can be done using a variety of thermal markers of immediate effect such as birefringence loss, collagen hyalinization, red zone formation, etc. that do not require survivial studies. [Table III]

Just as important to a successful outcome is choosing the best tissue to match the marker. Some investigations will be driven by 1) the particular disease process and 2) a specific organ or tissue in which the disease occurs. In those cases, the best thermal marker to use will be the one(s) that appears most reliably in that tissue. In other experiments involving 1) thermal lesion model testing and validation or 2) testing of energy sources or instrument design, the choice of tissue is determined by which marker will give you the best measurements.

\section{Statistically Valid Experiments:}

Biological tissues do not respond to heating or any other exogenous injury in a precisely predictable fashion as compared to metals or plastics. This is referred to as "biologic variation" and any investigator who works with living or dead biologic tissues has to compensate for the "variation" in her/his experiments. This is accomplished by 1) establishing strict controls to limit the number of experimental variables, 2) producing multiple lesions using exactly identical experimental conditions, 3) making multiple measurements of specific end points using consistent planes, reliable instruments and comparable locations to avoid measurement artifact.

Biologic and medical research is statistical research. Therefore, one experiment will not reveal truth but the average of multiple (preferably odd numbered) experiments will show important statistical probabilities. Statistically significant probabilities derived from appropriately controlled experiments are appropriate results to satisfy the clinicians, journal and grant reviewers and the Food and Drug Administration (FDA).

\section{Measurement of Ablation Lesions:}

Thermal ablation lesions can be made in all biologic tissues as long as the energy parameters fulfill the criteria for tissue ablation. Therefore, cheap, plentiful and clinically relevant target tissues, such as chicken breast and liver, can be used as long as they are not rotten (i.e. stored in the refrigerator for a month!) and their limitations as target tissues are understood.

Ablation energies produce holes, cuts and defects that can be measured grossly in either fresh or fixed specimens or microscopically in well-oriented tissue sections. Linear, 
volumetric or mass measurements are good estimates of tissue removal and, when done under well-controlled conditions, are very useful for comparisons.

Measurements of ablation depths and diameters can be obtained by using a little forethought and consistent techniques. Routine formalin fixation of biologic tissues and tissue processing techniques can cause swelling or shrinkage depending on the tissue. In addition, in musclular tissues, formalin fixation induces muscle contraction further distorting the lesion and the tissue precluding accurate measurements. Also, removal of fresh tissue from the animal releases normal tissue tensions that can also lead to artifactual collapse. Therefore, it is important to orient and support the tissues during the fixation and measurement processes. Fixation by organ perfusion may be necessary to prevent unwanted contraction and distortion of the holes. A good example is perfusion of the intact heart with saline to remove blood then fixative at systolic pressures to minimize the contraction artifact in transmyocardial recanalization experiments. Tissue slabs or skin pelts can be stabilized for fixation by pinning them down on a cork board before putting them into formalin. [Figure 9]

Single holes drilled into tissues will have a center of maximum depth. Therefore the lesion surface and bottom centers have to be identified to obtain accurate measurements. This requires careful dissection and orientation of the lesion and, in the case of small lesions, preparation of multiple serial histologic sections to obtain the exact section that represents the center of the lesion. [Figure 9] Larger lesions can be cut through the center freehand but it is difficult to make a perfectly perpendicular cut particularly in relatively fresh soft tissues as skeletal muscle brain or liver. A rigid, blunt-ended rod smaller than the hole diameter can be inserted gently into the hole and used as a guide to cut through the hole and/or marked to show the depth relative to the tissue surface. This gross measurement is best done in the fresh tissue since fixation can produce distortion leading to blockage to the passage of the rod. However, care needs to be taken to not push the probe past the bottom of the lesion: soft tissues such as brain and liver can be easily penetrated. Needless to say, sharp-pointed hypodermic needles are not appropriate measuring rods in any tissue.

Ablation hole diameters can vary because of 1) probe configuration, 2) laser beam profile (Gaussian vs "top hat) 2) mechanism of tissue removal and 3) tissue spreading, contraction and/or collapse during dissection or processing. This variation is particularly prominent at the upper portions of the lesion and is particularly bothersome in histologic sections of skeletal and heart muscle. Therefore, to obtain consistent measurements, multiple diameters should be measured in the straight portion of the hole and averaged for each lesion.

Special care should be taken to orient small lesions to obtain the best paraffin sections for measurement. Small coagulation and ablation lesions should be removed en bloc (whole 


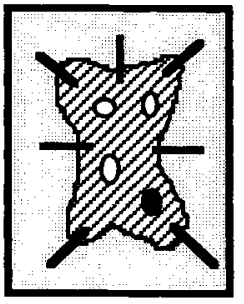

a

Surface View (a) and Side View(b) of a Skin Pelt Stabilized with Pins in Fixative

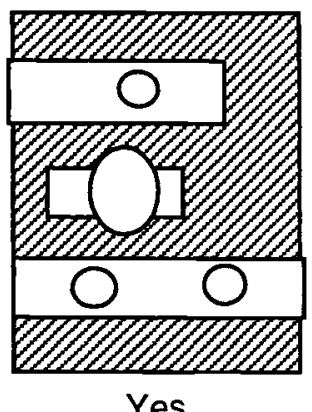

Yes

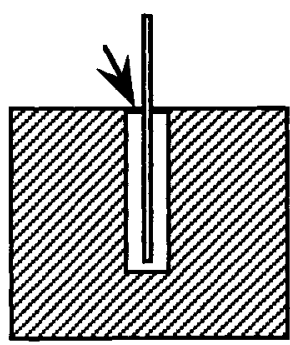

Gross Measurement of Ablation Hole

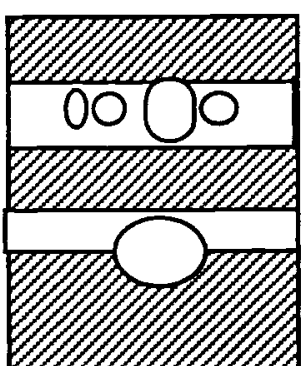

No

\section{Dissecting the Tissue for Microscopic Slides}

The lesions should be placed appart so that the thermal lesions do not overlap. The widest portion of the lesion should be included in the tissue block.

Do not cut the lesion in half because the widest diameter will be lost in sectioning.

\section{Figure 9}

Pointers on Preparing Tissues for Fixation and Microscopic Section Preparation

Plastic refrigerator containers with air-tight lids make excellent containers for formalin fixative. A layer of melted paraffin can be poured into a clean container to form a base to support the tissue and the pins. The containers with the paraffin will last for years.

The rigid rod can be marked at the surface tissue level (arrow) then measured. This procedure is not useful for small ablation holes which should be subjected to microscopic examination.

Many experiments are ruined because too many lesions are placed too close together on a small target tissue. Allow at least $0.5 \mathrm{~cm}$. between all thermal ablation and coagulation lesions. Frequently, excess tissue is trimmed from the paraffin block containing the tissue before sections are collected. If you cut through the exact center, then the first collected sections will not be representative of the lesion and measurements are not accurate. 


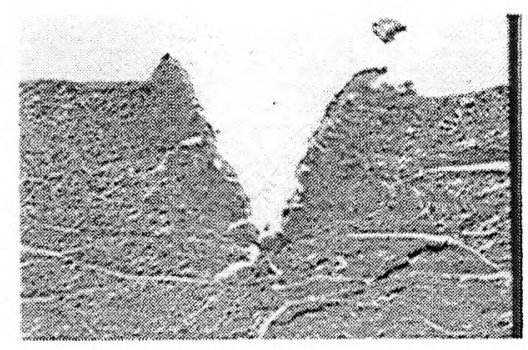

Light Microscopy

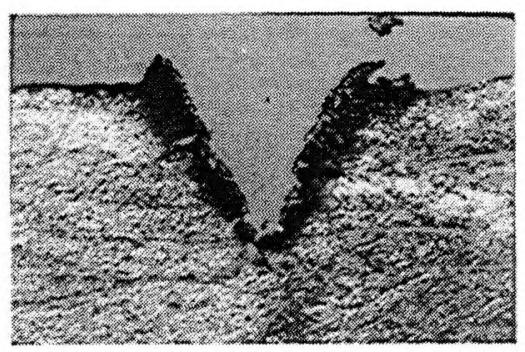

Transmission Polarizing

Microscopy

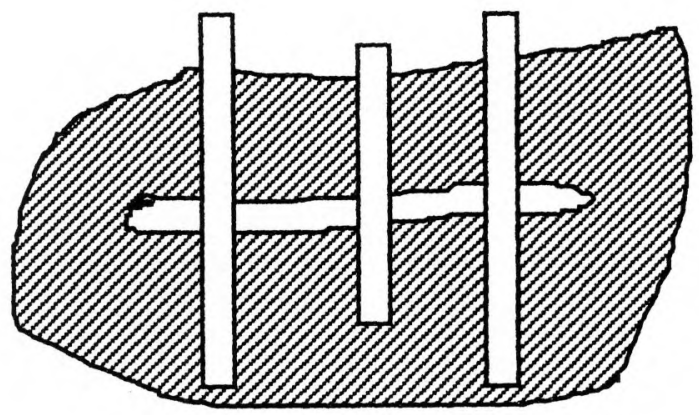

Representative Sampling Across a Thermal Cut

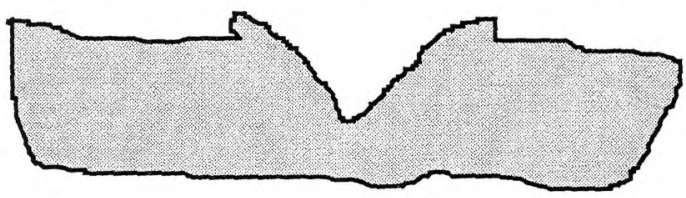

Profile of Transverse Cut

Perpendicular for DepthMeasurement

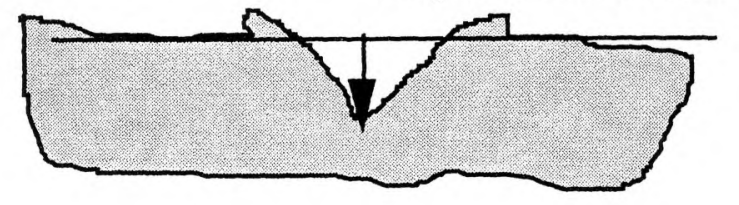

Measurement Points for Diameter and Depth of Cut

Figure 10

Proc. of SPIE Vol. $10297102970 \mathrm{H}-30$ 
lesion in center surrounded by tissue) and submitted for serial sectioning through the block. All sections should be examined to locate those few sections (usually two or three that represent the full depth and center of the hole. [ Figure 9]

Transverse sections of long cuts frequently have a $\mathrm{V}$ profile with splaying of the cut edges above the tissue surface. [Figure 10] This splaying is particularly evident in ablations in muscle tissues. When the edges splay out above the surface of the surrounding tissues, various approaches for measurements can be made. In general, surface cuts, particularly those made free-hand, will have variable depths therefore, multiple depth measurements should be made along the cut by looking at least 3 different points along the cut. The measurements will be best done in transverse sections of either fresh or fixed tissues observed under a dissection microscope (Mag. 2X-40X) or in paraffin sections representative of the entire lesion using a calibrated image analysis system or ocular micrometers. Either method requires using the same magnification for all measurements and measuring at the same locations for consistency.

The depths should be measured from a perpendicular dropped from a line defining the desired surface reference point. Whenever possible, the recommended reference point would be the tissue surface just beyond the splayed edges. Multiple measurements (at least $3 /$ histologic specimen) can be averaged with standard deviations calculated for comparison purposes.

\section{Structural Protein Thermal Coagulation:}

\section{Birefringence:}

The investigator has to be particularly careful in the choice and handling of target tissues in which partial or total loss of birefringence measurements will be used to map and compare treatments. Skeletal muscle such as chicken breast and cardiac muscle are highly birefringent while the smooth muscle of the urinary bladder and gut provides a fainter birefringence image intensitly. The investigator has to make sure that the tissue sections taken for polarizing microscopy are cut parallel to the longitudinal axis of the muscle cells where the native birefringence is at its maximum rather than in cross section. Clear boundaries of birefringence loss cannot be obtained in some tissues such as uterine myomas (fibroids) or myometrium yet birefringence changes can be described qualitatively.

Some stains can enhance the native birefringence of collagens and muscle although most measurements can be made on routinely prepared, hematoxylin and esosin (H\&E) stained paraffin sections. Sirius red intensifies the birefringence of collagen but the intensity may be too great in collagen rich tissues thus interfere with identification of partial loss 
boundaries. Mallory's trichrome stain provides a very bright orange birefringent image of skeletal and cardiac muscle but is not that useful for smooth muscle and collagen birefringence determinations. Sometimes it is necessary to prepare several microscopic sections and use more that one stain.

Cell Shrinkage and Epithelial Cell Spindling:

These thermally-induced cellular changes can be prominent with measurable boundaries in some tissues such as the epithelium of the urinary mucosa, cornea, bronchi, breast and prostate. Immediate fixation is mandatory for detection of heat-related cell spindling. Desiccation and post-mortum necrosis (rotting) and/or inadequate penetration of fixative will produce artifact that cannot be distinguished from thermal cell shrinkage. Fibroblast and muscle cell shrinkage occurs but is very heard to see. Histological artifactural effects from poor fixation, rough and delayed tissue handling and/or inadequate processing of pathologic specimens have bee responsible for many erroneous interpretations of thermal lesions.

Red Thermal Damage Zone, Necrosis and Wound Healing:

The red zone appears readily in various vascular organs and tissues such as liver, lung, glandular breast, prostate and skin. These vascular organs are useful for measuring boundaries of the red zone, tissue necrosis and wound healing in surviving animals. The lesions can be measured in situ at the time of heating and then sequentially in the same animal using various imaging processes or multiple surgeries. However, multiple surgeries can be detrimental to the animal and the various imaging techniques may not be adequate to show details of the lesion resolution. Therefore, to obtain meaningful information, multiple animals should be treated with the same parameters and then placed into groups with different survival intervals.

Variation Among Species and Different Tissues Within the Same Species:

The anatomy and physiology of various organs of experimental animals can differ considerably from their human counterparts. Therefore, it is imperative that the investigator realize the limitations imposed by these species differences. For example, collagen and elastin composition and distributions vary among different blood vessels within the same animal and vary between the same vessels found in different species. Another example, is that surface coagulation skin lesions on the backs of pigs heal slower than those on the belly skin of the same animal. Survival animal experimentation is necessary to test treatments and instruments but experimental results and therapeutic conclusions cannot be transferred automatically to humans. [36] 
Matching the Energy Source to the Clinical Need / 457

\section{CONCLUSIONS}

Numerous gross and histologic pathologic techniques are available to evaluate surface and interstitial thermal lesions produced in vitro, in vivo and in surviving animals. These techniques are valuable for 1) testing and validating mathematical and physical models and instrument design, 2) mapping treatment extent, 3) determining the mechanisms of thermal lesion production and resolution and 4) measuring treament efficacy. The identification of meaningful thermal markers and appropriate tissues that reflect clinical goals is an important factor in experimental design. The undeniable fact of "biologic variation" mandates using statistical approaches to experiment planning, execution and analysis.

\section{ACKNOWLEGEMENTS:}

This work was partially supported by grants and contracts from the Department of Energy, NIH, NSF, Texas High Coordinating Board, Valleylab, Inc., Biomedical Consultants, Inc., the Texas Professional and Business Women's Association and Radiotherapies, Inc. The author wishes to acknowlege the outstanding histotechnical work of Mirta Machado, Cindi Soto, Jeff Ellard and Kathy Nolan. A. J. Welch, John A. Pearce, Jenifer Kennedy, Thomas Ryan, Lihong Wong, Steven Jacques and Thomas Flotte have been invaluable collaborators, consultants and teachers.

\section{REFERENCES:}

1. J. A. Pearce. Electrosurgery. Chapman and Hall. London. 1986. pp. 1-258.

2. O. H. Wagensteen and S. D. Wagensteen. The Rise of Surgery. Universtiy of Minnesota Press. Minneapolis, MN 1978. pp. 3-52, 225, 274.

3. G. Majno. The Healing Hand. Harvard University Press. Cambridge, MA 1975. pp 1-571.

4. Caelius Aurelianus. On Acute Disease and On Chronic Diseases. I. E. Drakin, Ed. University of Chicago Press. Chicago. 1950. pp 1-1019

5. J. H. Breasted. The Edwin Smith Papyrus. University of Chicago Press. Chicago. 1930. Special Edition. Classics of Medicine Library. Gryphon Editions. Birmingham, AL 1984. pp 8, 365 .

6. R. S. Gottfried. Doctors and Medicine in Medieval England. Princeton University Press, Princeton, NJ pp 207- 244.

7. G. Muller and A. Rogan, Eds. Laser-Induced Interstitial Thermotherapy.. SPIE PM 25. Bellingham, WA. 1995. Pp.1-549.

8. T. P. Ryan and T. Z. Wong Eds. Thermal Treatment of Tissue with Image

Guidance. Proc. SPIE 3594:1-234. 1999 
9. S. Thomsen. "Mapping of Thermal Injury in Riologic Tissues Using Quantitative Pathologic Techniques." In Thermal Treatment of Tissue with Image Guidance. T. P. Ryan and T. Z. Wong Eds. Proc. SPIE 3594:82-95. 1999

10. D. W. Fawcett, A Text Book of Histology. 12 Edition. Chapman \& Hall. New York. 1994. Pp 1-964.

11. M.H. Ross, L. J. Romrell and G. I. Kaye. Histology: A Text and Atlas. $3^{\text {rd }}$ Edition. Williams and Wilkins. Baltimore. 1995. Pp 1-823.

12. A. Vander, J. Sherman and D. Luciano. Human Physiology: The Mechanisms of Body Function. WCB McGraw-Hill. Boston. 1998. Pp. 1-817

13. F. J.Netter, Atlas of Human Anatomy. CIBA-Geigy C. Summit, NJ. 1994

14. S. S. Sternberg. Histology for Pathologists. $2^{\text {nd }}$ Eitition. Lippincott-Raven. Philadelphia. 1997. pp 1-1200.

15. Hippocratis Aphorismorum. Sectio VIII. VI (The Aphorisms of Hippocrates. Tran. Thomas Coar. London 1822. Reissued:Classics of Medicine Labrary Grphon Editions, Ltd. Birmingham, AL 1982 pp 235-236.

16. A. J. Welch and M. J. C. van Gemert. Eds. Optical-Thermal Response of LaserIrradiated Tissue. Plenum Press. New York. 1995. pp 367-488, 609-902.

17. B-M. Kim, S. L. Jacques, S. Rastegar, S. Thomsen and M. Motamedi. "Nonlinear Finite Element Analysis of the Role of Dynamic Changes in Blood Perfusion and Optical Properties in Laser Coagulation of Tissue." IEEE J. of Selected Topics in Quantum Electronics 2(4):922-933. 1996.

18. S. Licht. Therapeutic Heat and Cold $2^{\text {nd }}$ Edition. Elizabeth Licht Publication. Waverly Press. Baltimore. 1972

19. G. Roussy and J. A. Pearce. Foundations and Industrial Applications of Microwaves and Radio Frequency Fields: Physical and Chemical Processes. John Wiley \& Sons. Chichester, UK. 1995.

20. P.N.T.Wells. Physical Principles of Ultrasonic Diagnosis. Acdemic Press. London pp1-282. 1976

21. R.S. Cotran, V. Kumar and T. Collin. Robbins Pathologic Basis of Disease. $6^{\text {th }}$ Edition. W. B. Saunders Co. Philadelphi. 1999 pp- 1-1425.

22. D. E. Ingber. "The Architecture of Life" Sci. Am. 278(1):48-57. 1998.

23. F. N. Ghadially. Ultrastructural Pathology of the Cell and Matrix. Vols. $1 \& 2$. $4^{\text {th }}$ Edition. Butterworth-Heinemann. Boston. 1997. 1-1413.

24. J. A. Pearce and S. Thomsen. "Rate Process Analysis of Thermal Damage." In Optical-Thermal Response of Laser-Irradiated Tissue. A. J. Welch and M. J. C. van Gemert. Eds. Plenum Press. New York. 1995. Pp 561-606

25. . Thomsen. "Pathologic Analysis of Photothermal and Photomechanical Effects of Laser-Tissue Interaction. Photochem. Photobiol. 53(6):825-835. 1991

26. S. Thomsen "Identification of Lethal Thermal Injury at the Time of Photothermal Treatment." In Laser-Induced Interstitial Thermotherapy. Eds. G. Muller and A. Rogan. SPIE PM 25. Bellingham, WA. 1995. Pp. 459-467. 
27. F. C. Henriques and A. R. Moritz. "Studies of Thermal Injury in the Conduction of Heat to and Through Skin and the Temperatures Attained Therein: A Theoretical and Experimental Investigation." Am. J. Jathol. 23:531-549. 194728

28. A. R. Moritz and F. C. Henriques. "Studies of Thermal Injury II. The Relative Importance of Time and Surface Temperature in the Causation of Cutaneous Burns. Am. J. Pathol, 23:695-720. 1947

29. A. R. Moritz "Studies of Thermal Injury III. The Pathology and Pathogenesis of Cutaneous Burns: An Experimental Study." Am. J. Pathol. 23:914-934. 1947.

30. F. C. Henriques. "Studies of Thermal Injury. V. The Pridictability and Significance of Thermally-Induced Rate Processes Leading to Irreversible Epidermal Injury. Arch. Pathol. 43: 489-502. 1947.

31. G. E. Pearse. Histochemistry. Volumes $1,2 \& 3.4^{\text {th }}$ Edition. Churchil Livingson. New York. 1995 pp 1-1055. (Vol. 1 \&2 1991 1-728)

32. J. D. Bancroft and A. Stevens. Theory and Practice of Histological Techniques. $4^{\text {th }}$ Edition Churchill Livingstone. New York. 1996 pp 1-766.

33. J. D. Bancroft and H. C. Cook Manual of Histological Techniques and Their Diagnostic Application. Churchill Livingstone. New York. 1994 pp. 1-457.

34. S Thomsen, J. A. Pearce, R. Randeri and E. Chan. "Determination of Isotherms of Thermal Damage." Proc IEEE/LEOS. 2295-2296. 1995

35. I.K. Cohen, R. F. Diegelmann and W. J. Lindblad. Wound Healing: Biochemical and Clinical Aspects. W.. B. Saunders,Co. Philadelphia. 1992 pp 1-630.

36. J. A. Pearce and S. Thomsen. "The Effect of Vessel Architecture on Fusion by Radio Frequencey Current." SPIE Proc. 3249:217-228. 1998 